JOALL (JOURNAL, (DF APPIIED IINGUIS'IICS ANI) LI'TERA'TURE)

Vol. 5 No. 2, 2020

ISSN (print): 2502-7816; ISSN (online): 2503-524X

Available online at https:// ejournal.unib.ac.id/index.php/joall/index

doi: http://dx.doi.org/10.33369/joall.v5i2.11447

\title{
INTERNET-BASED APPROACH IN DISTANCE LEARNING OF PARAGRAPH-WRITING COURSE AT STKIP MUHAMMADIYAH BARRU
}

\author{
Siti Hardiyanti Amri \\ STKIP Muhammadiyah Barru \\ Corresponding email: sitihardiyantia1@gmail.com
}

\begin{abstract}
The era of COVID-19 transforms the traditional classroom into the fully online distance learning system. This new learning mode presents new challenges to both the lecturer and students at the College of Teacher Training and Education (STKIP) Muhammadiyah Barru, Indonesia. This research focused on identifying the types of online platforms applied in distance learning of paragraph writing course, the students' behaviors and challenges toward the learning system, and the English skill output of the learning process. The method was qualitative descriptive consisting of data collection and data analysis. The data was gathered by interviewing and observing the participants. The data was then analyzed by using distance learning concepts of Cynthia White. The result indicated that the class made use of Multi-synchronous distance learning. However, they preferred to make use the asynchronous distance learning due to the flexibility of time and space, also its cost-effective. Besides, the research found that the students fast adapted to the new learning context for the ability to operate technology, yet they did not fully understand their roles and responsibilities during the learning process. Moreover, as the challenges of self-independent demand, self-awareness and management and the slow internet access of their isolated areas, most of the students did not show satisfied output in writing English paragraph.
\end{abstract}

Keywords: Distance learning, internet-based approach in English learning, Cynthia White, multi-synchronous distance learning, writing course.

\section{INTRODUCTION}

Work from home and study from home become new normal since covid-19 outbreak. In educational world, a huge shift occurs from face-to-face learning activities to online learning. The sudden change forces educators to creatively think about the alternative teaching media. In the new learning mode, the use of internet is highly increasing. Internet connection becomes the essential part 
of distance learning which enables the users to interact beyond time and space. It offers the most possible and suitable way to conduct academic activities during the pandemic situation. Distance learning suddenly becomes popular method characterized by the absence of teacher in the real classroom situation. Holmberg et al. (2005) further explained the constituent elements of such learning mode that are either the conventional course material delivery in printed form or audio, or synchronous and asynchronous online media (video conferences, email, or Google classroom).

The online learning certainly requires ability to operate various digital platforms which can be easily accessed through internet. As the part of contemporary society, teachers and students are easy to adapt to the new learning mode for those platforms are the vein of their everyday life ranging from entertainment, information, to social communication needs. People living in the industrial revolution 4.0 grow with technology. It makes their lives easier accessing information and developing new skills. In educational aspect, it provides opportunities to broaden knowledge and social network. The use of technology particularly internet will be constantly growing for its cost, time, and space efficiency (Lehman, Rosemary M., Conceicao-Runlee, 2010). Nevertheless, the institution planning to conduct distance language learning needs to prepare the well-designed course materials for the challenges start to happen in the adjustments of them from conventional class to fully digital one. Also, online learning system requires autonomy and selfinitiating of students.

Distance learning is certainly not a new method of learning, yet most higher educations in Indonesia specifically South Sulawesi have not implemented it yet. In this case, The College of Teacher Training and Education Muhammadiyah (STKIP Muhammadiyah) located in Barru regency does not apply blended learning, or the combination of online-based class and traditional place-based classroom. The university teachers then experience the sudden transformation to deliver all course materials via online and most students hardly participate for the slow internet connection in their region.

The use of technology in language teaching such as tape recorders, language laboratories, and video has been long applied since 1960s. It continuously evolves to computer-based teaching method commonly known as CALL (Computer Assisted Language Learning) in the beginning of 1980s. The language learners simply complete all the tasks provided in the computer and the machine directly gives feedback to the learners. The popularity if ICT in language teaching drives the birth of more sophisticated one that is now internet and web-based tools generally known as TELL (Technology Enhanced Language Learning) firstly appeared in the 1990s. The use of internet as the medium of language learning is constantly growing for it is 
easily accessed both at home or public facilities. Internet thus becomes the part of modern society's life (Dudeney \& Hockly, 2007).

Internet is one of approaches in distance learning, the learner-centered learning method. Williams, Paprock and Covington define the term as the situation in which the teacher and the learners are separated by time and space. It thus requires students' autonomy to understand the course materials and to complete the tasks virtually handed out by teachers. Distance learning is carried out when it is not possible for the teacher and learners to meet in the real classroom. Shelley further states that this mode of learning is hence more flexible in the process. The learners independently access information and range of supplemented materials from internet. Both teachers and learners can also set up the agreed time to conduct the class (White, 2003). In addition, the leading theorists such as Borje Holmberg, Charles A. Wedemeyer, and Michael G. Moore (Moore \& Anderson, 2003) assert that the distinct characteristic of distance learning is the centrality of the students. It means that the success of the learning process lies on the students themselves. They need to understand their strength and weakness and to design their own strategy in order to master the target language. Furthermore, since distance learning is carried out in the distinct place zone, it is divided into two learning process that are synchronous learning conducted in the similar time set and asynchronous learning which can be accessed at any time.

Lamy and Goodfellow propose that asynchronous distance language learning is the learning system which can be accessed at flexible time and place. In such learning process, the teachers and learners could take advantage of computer-mediated communication such as e-mail, discussion lists, computer conferencing and bulletin boards. Besides communicating with the same group of learning, learners also have opportunities to communicate and to practice their language skill to the global learners, also the native speaker. The benefit of this type of learning is that the learners can take part in the discussion at any time, or not limited to fixed time (White, 2007). The extended space during distance learning requires the extended time. Asynchronous mode of communication is considered as the essential part of e-learning for the extended time. The interaction between teacher and learners is not established in real time (Jung, 2019).

In synchronous distance language learning, the learning process is established in particular time, for example by telephone or chat rooms. The time is controlled and limited. Both teacher and learners communicate in the given time duration. Teacher in this case could directly deliver the course material, and the students give respond to it. Meanwhile, the feedback of teachers in this kind of learning process is highly required. Not all the learners prefer such real time interaction due to the time limit, yet others find it more interesting, motivating, and feeling less isolated (White, 2003). 
Multi-synchronous, the term coined by Mason, is the mix of synchronous and asynchronous method. Those two expose students with the various forms of language learning media. A satellite television Internetbased distance language program called English Business Communication developed by Christine Uber Grosse (2001) is an example. The program combines the synchronous system that are face-to-face virtual meetings, interactive satellite television and the use of internet-based web board to communicate during office time, and the asynchronous ones that make use of internet-based web board for posting and reviewing homework and for class announcement, e-mail for sending messages, homework, and feedback on submitted work (White, 2003). Since the limited time of synchronous media of communication, the students may find it difficult to remember the materials having been explained by the teacher. Meanwhile, in asynchronous mode, students can easily re-access and re-read the posted materials whenever they want. However, teacher can give direct response, address the students' need, and understand the students' emotion in synchronous live chats and video conferences (Demiray \& Sharma, 2008).

Teacher and learners definitely experience challenges in distance learning context since the lack of real guidance, interaction, and prompt feedback. Distance learning makes learners feel isolated for the absent of real social interaction. In regards to the absence of teacher, the students should fully understand to adjust their learning attitudes. They should independently learn and match the obtained sources with the course goal in order to achieve the total understanding of target language. Furthermore, the other challenge is self-management since the students should be aware that they hold control over themselves. They must manage the course and their learning behaviors. Also, the operation of technology requires particular skills. Both teachers and students should continuously learn and adapt to the new technology (White, 2003).

Technology positively impacts the educational world. Social media and video or text-based conferences increase the collaborative learning. Several platforms are regarded beneficial and effective in their applications (Huang et al., 2019). In addition, computer network may offer more opportunities in the process of learning a new language, yet it does not assuredly lead learners to master the target language. Internet for example is like any other technological tools used in teaching such as pencils, paper, and blackboards in early time to projectors, and tape recorders later. Internet itself does not guarantee and automatically improve the language skills of learners. Further researches should be conducted to study the use of technology in particular context by analyzing the learners, the target language, their attitudes and activities, the goal, setting, motivation, and the language learning outcomes (Warschauer \& Kern, 2000). 
There are several researches who have studied about internet-based distance learning. Ekmekçi (2015) conducted research on EFL learners' contentment and assessment toward distance English courses. The research indicated that distance English course was more favorable and interesting. The major factor of students' interest was the time and space independence. Along with the contentment, the challenges also arose regarding the poor assignments and grading technique. However, this research only focused on one type of distance learning and did not explore more about the students' English improvement.

Besides, Zhong (2008) examined about learner's autonomy in learning English by using internet access. He found that such approach in improving English skills was effective as the supplement of traditional face-to-face learning environment. In addition, the various English materials helped students to study based on their English level. The other research studied about the use of technology in English learning. Ahmadi (2018) proposed that the learners' English skill was well upgraded by the help of technology. In terms of its benefits, technology offered attractive and flexible method of learning, furthermore; it also developed students' independent, initiative, and responsibility. These both researches nevertheless proposed the beneficial aspect of technology regardless the possible challenges during its implementation in the learning process.

The study about the potential of ICT in ELT was also conducted by Nguyen (2019). The research focused on the use of ICT application such as Facebook and Google Docs in the learning of collaborative writing. In a Vietnamese EFL University, the use of ICT was highly required to foster students' writing skill. This research nonetheless investigated the use of supplementary asynchronous media in improving English language teaching and learning and did not explore more about any synchronous ones.

Sritulanon et al. (2018) also conducted other interesting research about English teaching model in distance education. They analyzed the use of video conferencing technology to teach English speaking in distance course system. The findings were five major components in the proposed English-Speaking Teaching Model (ESTM) that are; 1) language awareness promotion, 2) vocabulary and language pattern development, 3) language application development, 4) lesson delivery and 5) cooperative and collaborative learning. Nonetheless, speaking also involves body language and engagement which should be explained as the barriers in distance learning of speaking course.

In addition, the recent study was established by Altunay (2019) regarding the Turkish EFL students' perception about distance English learning. The questionnaire data exhibited that the students preferred traditional face-to-face learning context than distance learning. Otherwise, the 
interview showed that distance learning method was more preferable in terms of time and place effectivity. Moreover, the challenges were faced by them concerning on technical and facilities issues. However, this research did not give any further explanation about both synchronous and asynchronous learning approach.

Based on the relevant researches above, there had not been any study which offered multi-synchronous approach of distance language learning which would be further explored in this research. This research also concerned on the challenges and the students' English output from such type of learning. This study is thus highly required and essential to learn more about the new approach in order to be possibly applied in the future learning system. Furthermore, based on the background of research, the research questions are; 1 . What are the types of digital platforms used in distance learning of Paragraph Writing course? 2. What are the students' challenges toward this learning mode?

\section{METHODS}

The type of research is descriptive qualitative research. Qualitative research focuses on the interpretation of phenomenon. It does not deal with survey and the number of identified subject. It observes and studies the experiences of subject (Merriam, 2009). Additionally, the instrument of qualitative research is the human researcher. The researcher is the main core of the research who plans the research, observes the situation, interviews subjects, organizes the ideas, and writes the reports. Qualitative research is thus known as interpretative research since it relies on the researcher defining and redefining what he sees and hears (Stake, 2010).

In addition to explanation above, descriptive qualitative research is the type of research which describes the research data by words instead of numbers. The researcher functions as the key instrument who analyzes and observes the subjects of research in order to get the total understanding and interpretation. The research methodology consists of data collection and data analysis.

\section{Data Collection}

This research uses two methods in collecting the data. The first method is interview of the target learners. The research interview functions as the primary means of collecting information related to the research objectives, or as Tuckman proposes it gives information about the thought of a person (his knowledge, experience, preferences, values, attitudes, and beliefs). Interview is also used to examine the hypotheses and to identify the relation of variables. Last, Kerlinger suggests that interview may generate additional results in regard to the respondents' motivations and behavior (Cohen et al., 2017). The 
participants of this research were the second semester English Education students at STKIP Muhammadiyah Barru, Indonesia. The interview was conducted to 5 students who were taking paragraph-writing course. They shared their opinions and experiences during online distance learning.

The other method is observation. Observation provides opportunity for researcher to collect direct data from direct situations without mediation. It helps researcher to deeply observe and learn the situation. Through observation, the researcher goes deeply into the things that participant do not probably openly and freely talk about in interview session (Cohen et al., 2017). The researcher was the lecturer of paragraph-writing course directly observing the process of distance language learning with internet-based tool. The observations focused on the students' response, behavior, and attitudes during the virtual class. This research thus combined these two methods in order to gain deep understanding of the research context.

\section{Data Analysis}

The data of this research were analyzed according to the theory of distance language learning of Cynthia White. The first research question was answered based on the concept of Synchronous, Asynchronous, and Multi-synchronous learning. White (2006) proposes that a synchronous internet-based conferencing system as the learning process which takes place in the fixed and agreed time. Meanwhile, the asynchronous learning system transcends time and space since the students can access the course material anywhere and anytime. The online distance learning of paragraph writing course utilized multi-synchronous learning (both asynchronous and synchronous media).

The second research question was answered by the several challenges in distance language learning mentioned by White (2003). The possible challenges are; 1) the immediate demands which relates to the learners' roles and immediate understanding in the system of distance learning, 2) absence of teacher mediation in which the interaction of teacher and students in distance learning context differs from conventional face-to-face classroom. The teachers do not immediately present to deliver course materials and guide students in the process of learning, 3) self-awareness and selfmanagement which means that this new type of learning requires more selfautonomous than classroom system. The students must understand about self-centered distance learning, their roles and a set of responsibilities, 4) the new technologies which break the border of time and space. A wide variety of e-learning systems are now available for distance learning. The development of technology provides new opportunities toward interactive and collaborative works among learners. However, the challenge seems to appear regarding self-initiative and motivation both lecturer and students to upgrade their skill in order to operate new technologies. 


\section{FINDINGS}

This research identified that the lecturer and the second semester students of English education program at STKIP Muhammadiyah Barru used so-called multi-synchronous platforms during paragraph-writing course. However, the learning process was mostly asynchronous. The two methods of learning are explained more as follows;

\section{Multi-Synchronous Learning Asynchronous Learning}

During distance learning of paragraph writing course, the lecturer and students regularly used WhatsApp. The lecturer used WhatsApp to explain about the course outline and regulation. It was continuously used to give instruction about the course tasks. The other application used in this online learning process was Google Classroom. It was the primary means of course delivery. The course materials of paragraph-writing were all distributed in Google classroom. Besides, the lecturer also attached self-voice recording explaining about the structure of paragraph (topic sentence, supporting sentences, and concluding sentence) to make students more understand the subject matter.

The other supplemented medium of English writing practice was Steller application. The followings are the examples of students' stories in Steller.
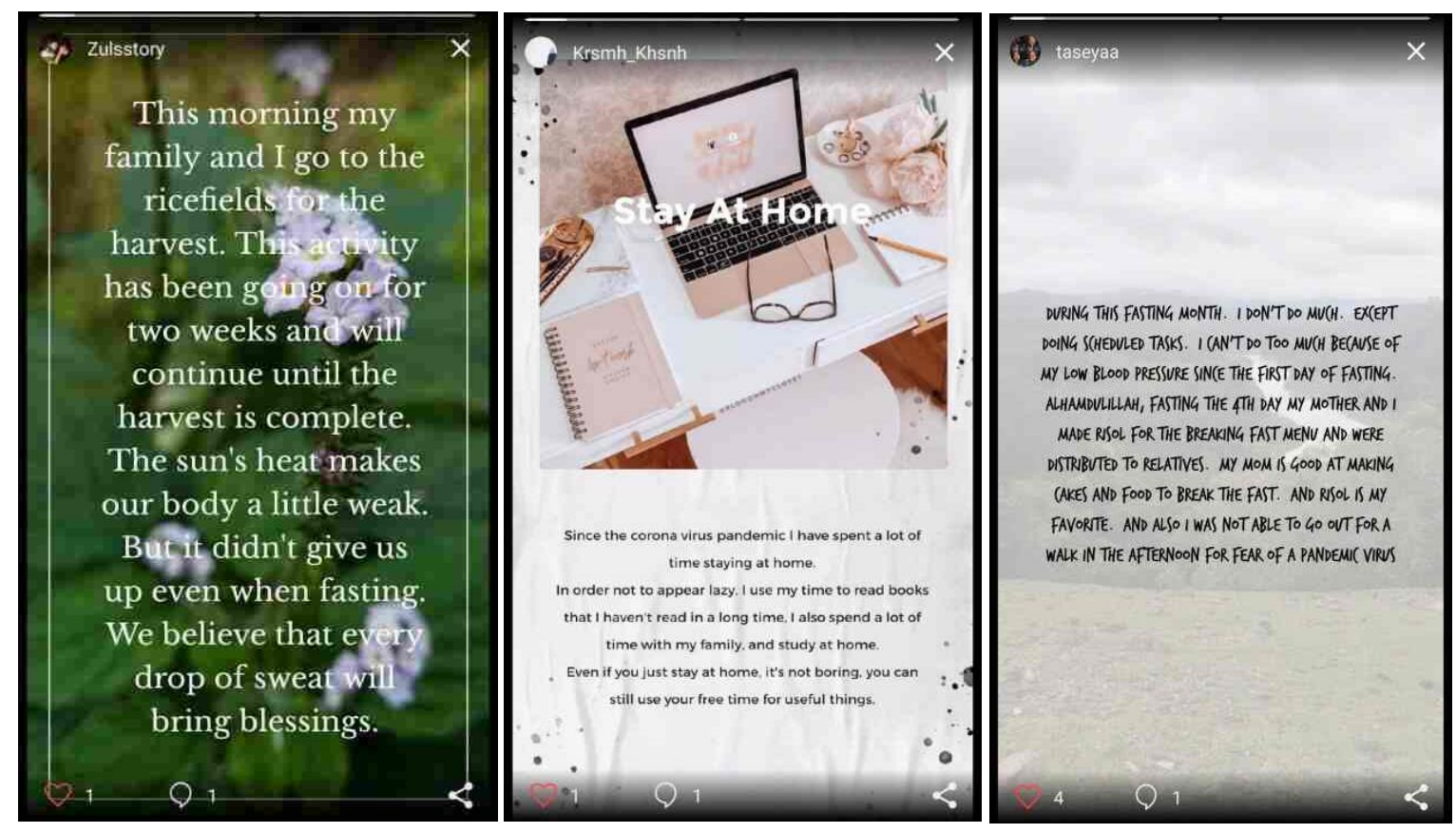

In paragraph-writing class, the lecturer assigned the students to write stories in Steller app two times in a week during Ramadan month. This story 
telling assignment was evaluated as the mid-term test. They wrote about their experiences and activities without worrying about paragraph unity, coherence, and tenses. They practiced to explore their ideas and creativity in this platform.

Lastly, the online learning process also used the blogging platforms as the final writing task. The students freely chose to write about any type of paragraph they had learned such as narrative, descriptive, definition, process, and cause and effect paragraph. The followings are the examples of students' works.

\section{Writing 1}

What Do You Know About Your Place of Birth?

There is an interesting question asked by a student recently. That question seemed to shake me to the point of losing my confidence about who we really are. The boy asked, "Is it true that being born somewhere correlates directly with our knowledge with that place?" something like that sounds the question.

This question "strikes" my feelings. I was born in Barru, a beautiful city full of great history. But, do I already know everything about Barru Regency in its entirety both geographically and socially? Apparently not! I don't know everything about Barru Regency in its entirety. Although, Barru is my birthplace.

I was born in Barru in 2001, a city in the province of South Sulawesi, a city known by its motto "HIBRIDAH" (Hijau, Bersih, Asri, dan Indah). There is something interesting about this city, which is a monument that has become an icon of this city. At the top of the monument, there are four golden umbrellas as a symbol that is characteristic of this city monument. Do not think that the four umbrellas indicate that Barru is a city of rain, because the city of rain is Bogor, not Barru. The four umbrellas mean the four kingdoms that once existed in Barru district during the Dutch colonial era. The four kingdoms which became the forerunner to the founding of Barru district and its history are enshrined in the form of a fourumbrella monument.

In the city of Barru there is also a monument called the Colliq Pujie monument and the park which also has the same name, the Colliq Pujie Park. At first glance that name is very foreign to me, because in history since I was sitting in elementary school, junior high school until high school, the history of Colliq Pujie was never discussed. Let alone its history, its name has never been mentioned so that the name Colliq Pujie is so foreign to me.

I always wonder who is Pujie Colliq? How big is the service until in Barru district a monument and park are named Colliq Pujie. And those questions were only answered when I was in college narrated by a lecture with a local content course. It turns out that the service of Pujie Colliq in the literary world is the name of Indonesia in the international world for his hard work together with b.f Mathes copying ancient Bugis manuscripts and epic stories that are rumored to have a length exceeding two similar genres from India namely Mahabarata and Ramayana. But who is she? What does this have to do with the new district? Colliq Pujie turned out to be the son of the Tanete king (one of the kingdoms that became the forerunner to the founding of the Barru district) named La Rumpang. Look, so great history is stored in this city, and this is only a small part of the history of the new district that I know. And there are many more histories and even interesting things from this city that I don't know yet.

Each region has a history, as well as a new city. If we want to learn and find out, then we will find a lot of great history that is stored and is amazing. So, it is unfortunate when new generations do not know and do not want to find out about the history of the faithful behind this city. But unfortunately, the interest of the younger generation towards history is very low. So many of Barru's own generation, who do not know about the history that is kept behind the city of his birth. Whereas, learning history is nothing but digging values in historical 
events or learning how historical figures face life and make history. If the young generation does not have the enthusiasm in studying history, then history will only be recorded in the pages of the book without being remembered by the latest generation. Therefore, our knowledge of our place of birth depends on each of us, whether we want to learn and find out or just be very stupid.

"History must not be forgotten, because history is part of the nation's character that cannot be lost."

The first writing was published on Tumblr blogging platform. It was the longest writing for it consisted on several paragraphs which constituted an essay. The following work was the type of narrative paragraph published on Blogger.

\section{Writing 2}

My Experience in Home at Night

At 2 am in the morning I suddenly woke up because I heard an unusual noise coming from my kitchen. I was confused and scared because my whole family was going to my grandmother's and I missed out on an appointment with my friend the next day. At first I tried to ignore the sound. I put a pillow over my head. I guess what I did was work out. But "break" I heard the sound of the dishes falling. I can't take it anymore either. Soon I woke up from my bed and I picked up a baseball bat next to my bed. Then I sighed deeply and emboldened myself to go to the kitchen.

The closer I get to the kitchen, the more I hear the sound. My fear is growing. My body sweat grew faster and my heart rate grew stronger. When I got to the kitchen door, I saw a rather large shadow on the wall in front of me. My guts are getting thinner. I take my feet away and when I leave the place. It just grabbed me from behind. He threw me in the back of my leg and made me fall. I didn't know what else to do back then because my whole body went limp. I thought I'd pass out for a second. But then I heard "meow, meow" and it turned out that what hit me and made all that noise in the early morning was a cat. I was upset with the cat, but I was a little relieved that it was the image of a cat.

The other three students also decided to publish their writings on Blogger. It was simply created as long as they have Google account. Besides, the students also found it easy to manage.

\section{Writing 3}

How to Create a Blogger Account That is Fast and Practical.

In creating a blogger account, you can follow these fast and practical steps. First step, you need to access the blogger website at https://www.blogger.com/. Second, when the website already displays the blogger page, click the Create Your Blog button. The third step, you will be directed to log in your Gmail account. Then, just enter your g-mail username and password. After that, you need to confirm the blog profile. You just fill in the available fields with the name of the blog you want to display. Then click Continue to Blogger. When finished, you will find the Welcome page. To continue creating a blog, click the Create New button. In the Title section, enter the title of the blog that you want to develop. This title will appear on the front page of the blog. Then in the section, enter the URL that you want to use as the blog address. This address will automatically be followed by the extension.blogspot.com. Then in the Theme section, please select the theme you want to use on the blog. As you wish. After 
everything is filled in, click Create Blog! Congratulations, you already have your own Blogspot page.

\section{Writing 4}

\section{Rice Process}

Rice, which is our staple food daily, must go through several processing processes before becoming rice. The process is quite long and requires quite a long time. This process begins with preparing the fields to be planted with rice seeds. Farmers have to plow their fields using buffalo or tractors to be fertile. After that, farmers will make pattern lines to grow rice. This is done so that the seeds planted neatly arranged and the distance is not too close. Then the farmer will plant the rice seeds in accordance with the place that has been marked. They planted it backwards as not to step on the seeds that had been planted. After all the seeds are planted, the next process is treatment. Farmers will wait for their rice fields for about six months while taking care, such as providing fertilizer, watering, and eradicating pests. After the rice turns yellow, they will harvest it. Until finally the rice is changed to rice and only then can we cook it into rice.

\section{Writing 5}
The Owl
I have learned many facts about owls. First, most owls are nocturnal which means they hunt at night. Next, owls cannot move their eyes on the socket so they must turn their entire head. Finally, the smallest owl is the Elfowl which is 6 inches long and gas a wingspan of 15 inches.
Owls are very interesting birds.

The above works were the sample of process paragraph. The former writing explained about the steps on creating a blogging account and the latter one talked about how rice was made. The last writing was the shortest paragraph.

\section{Synchronous Learning}

Online synchronous media are video or audio conferences. The synchronous learning identified in this research was zoom application as a means to deliver the course materials by video conference. The lecturer and students dealt to virtually meet at the agreed time. After the students were assigned to write five paragraphs about any chosen topic through Google classroom, the lecturer found out that their writings had not met the correct pattern. The lecturer then decided to use zoom to re-explain the materials and to make students more understand about the correct paragraph structure and unity. All students were able to join the video conferencing, yet the online class was conducted in different day due to the different need of students. There was a male student known having struggled to understand the course material. Therefore, the certain approach was needed in teaching him. The first zoom meeting was specifically designed for him in order to deeply explain the material.

Furthermore, the second and the third zoom meeting was attended by two students in the former and three students in the later who are considered 
easy to comprehend the whole online course material. The lecture only focused to discuss and review about their previous writing task. The lecturer shared their works through the screen and pointed out their mistakes regarding of the lack of unity in their paragraphs.

\section{Challenges in Distance Learning Immediate Demands and Absence of Teacher Mediation}

The shift from traditional face-to-face classroom to fully distance learning with internet-based approach required immediate adjustment. All students were not ready to face this new learning method. The interview conducted to five students showed that they preferred conventional classroom rather than digital one.

\footnotetext{
Lecturer: Which one do you prefer, online learning or face-to-face learning?

Student 1: $\quad$ Learning directly in class because we can meet face-to-face with the lecturer and friends.

Student 2: $\quad$ Belajar secara langsung karena lebih mudah untuk memahami penjelasan dari dosen.

[I prefer face-to-face learning since I can easily grasp the lecturer's explanation].

Student 3: $\quad$ Face-to-face because it does not make me tired of learning.

Student 4: Belajar secara langsung. In my opinion, face-to-face learning membuat kita paham secara langsung dan lebih rinci untuk mencerna pelajaran.

[I prefer face-to-face learning. In my opinion, we can directly comprehend the subject]

Student 5: $\quad$ Actually, I like learning face-to-face, I feel free to ask If I have question and easy to know the subject, but in this pandemic situation, we do not have other choice.
}

For most students, the fully online class of paragraph-writing course was difficult to adjust to as they had not been previously prepared. Besides, they felt isolated and could not socialize with their peers. They liked traditional classroom environment better than online for they could immediately response the lecturer 'explanation and got direct feedback.

\section{Awareness and Self-Management}

Distance English language learning required the students' awareness to manage their learning attitudes. In the case of the research conducted on the second semester students from English department, they had less awareness and self-management in learning process.

\footnotetext{
Lecturer: Did you find any obstacles in adapting to this new learning mode?

Student 1: Yes, I faced many obstacles on Google classroom and zoom.

Student 2: Internet access!

Student 3: Bad network so that it slowed down the process of carrying out the task.

Student 4: $\quad Y$ a, seperti zoom yang sering terputus dan steller yang tidak bisa memuat.
} 
[yes, zoom video lagging and slow loading steller].
Student 5: $\quad$ I had obstacles in this new learning mode, all about schedule and time.

Slow internet connection became a greater challenge for most students during the learning process for the internet facilities were not widely available in their area. Some of them struggled to join the video conference, and the class occasionally ended up in text-based conference for the bad connection.

\section{Border Crossing and the New Technologies}

The followings are the answers of students in interview session about their experience in operating the digital platforms during distance learning of paragraph writing course.

Lecturer: What did you think about the use of internet (online applications) to learn paragraph writing subject during pandemic situation? Did you find any obstacles in operating the online apps?

Student 1: In my opinion, internet was very useful. It was the learning medium which could connect us with other friends. The benefits were practical, enjoyable learning experience, saving time and money during social distancing. I did not find any trouble with WhatsApp and Steller.

Student 2: The problem was only difficult internet access.

Student 3: Very Good!

Student 4: I was running out of internet data plan.

Student 5: It was interesting but I got difficult to get internet access in my region.

In connection to the research, students were not difficult in using WhatsApp since it had been long used as the additional medium for communication during the face-to-face learning process. Also, Google classroom and blogging platforms were not new for them since they had been used as the supplemented medium of learning in the previous semester. Students submitted their task in the Google classroom and they had used blogging platform to practice their writing skill in the previous writing class.

In addition, in this paragraph-writing class, the students newly learned to operate Zoom and Steller application. They easily learned and fast adjusted to the internet-mediated distance learning. The challenge did not lie on the required skill to operate the latest online platforms, yet the internet connection to access them. In the interview session, the students talked about their difficulty to connect to several online learning media due to the slow internet connection in their isolated region. The poor connection delayed the Google classroom notification and the process of submitting task. It required also stable connection to smoothly run Zoom video conference. Since internet connection was not widely available in Barru regency, the students should regularly buy internet package provided by their mobile phone carriers. 


\section{DISCUSSION}

The sudden COVID-19 issue makes all the academic stakeholders to immediately think about the solutions in order to be able to establish academic activities from home. Online distance learning becomes the best and most appropriate way in response to the problems faced by the educational world. White \& Reinders (2010) states that technology of internet is efficient in time and cost. It enables the educators to conduct the learning process when it is impossible to meet the learners in actual classroom situation. Both lecturer and learners could feel the sense of being there through digital platforms. Inglis (cited in White, 2003) formulates the term online learning to explain about the learning process which makes use internet technology to not only access information and course materials, but to establish interaction and collaboration with peers. Internet hence is the essential part of the online learning for it offers a number of digital platforms which can be used as the media to English language distance teaching and learning.

There are a lot of diverse social media platforms which can be utilized as the media of English learning. The use of Whatsapp was not new in the process of learning at SKTIP Muhammadiyah Barru for its flexibility to convey information, to deliver and to access the course material. The students simply opened and checked their whatssapp to get the latest information about the course whenever they had time and wherever they were. Whatssapp was used as the supplementary communication media. It was used to remain students about the recent posts in Google classroom in case they turned off their notifications. The other advantage of whatsapp was it provides whatssapp info so the lecturer could check about the number of students who had read the message. It helped the lecturer to monitor and to make sure that the information was read by all the students even though they did not give direct response or comment.

Moreover, the students easily accessed the course materials from Google Classroom. Since distance learning required students' autonomy and initiative, the early tasks required them to independently read the writing handbooks, to review them and to complete the quiz of each topic in the book. The lecturer expected them to have a brief understanding of the materials by themselves before starting to write their own paragraph. The students were then easy to submit their writing tasks and the lecturer was easy to monitor the students' learning progress in the Google classroom. In Google Classroom, lecturer could automatically set a task deadline. Students could easily submit their assignment in the given time. Besides, they could also leave private comments to the lecturer regarding the tasks.

The learning process also made use Steller app which was not conventionally used as the lecturer should creatively think about learning medium for writing was one of English skills which required more practices. 
Steller not only offered students with interesting template to share their stories but also the opportunities to interact with other users which were mostly the native speakers of the target language. In addition, the students could both explore their ideas through storytelling and their creativity to design attractive background. It certainly made writing learning process more fascinating for them.

Warschauer and Meskill (cited in Rosenthal, 2013) explain that electronic communication using asynchronous tools is regarded as the alternative replacement of traditional classroom. It offers various tools which could support the language learning. Since it takes place outside of classroom context, it can enhance the students' experiences in practicing the target language. Alsagoff et al. (2012) further explain that the use of digital media improves the students' independence and creativity. The use of Steller encouraged them to be involved in and to interact with people outside of classroom. The final task which required the students to publish their writing on the blogging platform also enhanced their networks, they could still make use their blog to express their ideas and share their writing to publics. Also, they could use the blog to the next writing class and it was considered as the best platform to continuously practice their writing skill. However, those digital platforms were not enough in the process of online learning. The lecturer also held synchronous class sessions.

Synchronous type of learning requires the management of time and place. This type of online conference accommodates a great number of people (Negash et al., 2008). The advantages of synchronous platforms are the lecturer can give direct feedback and comment. People also feel less isolated for the visual and aural prompt. However, the geographical location, the passive students, and the difficult control of large group are also some issues regarding such type of learning (Rogers et al., 2009). One of the advantages of zoom, a lecture could share the course materials on the screen. The power point slides were thus prepared to make the learning process more interesting and the material could be easily understood by the student having difficulty to follow the lecture. The first zoom meeting length was longer than the later ones in order to slowly explain the basic knowledge on how to write a good paragraph and the rest of the meeting was only free talk about the student's condition and difficulty during the learning process. This virtual face-to-face by zoom video made student feel less isolated and more emotionally motivated. The support of a lecturer was strongly required in the adjustment of this fully internet-based learning. In discussion session via zoom, the lecturer observed that the students obtained comprehensive understanding by re-explaining the material through video conference. Shortly, the lecturer observed that the synchronous learning method such as zoom was also essential in internet-based learning. It functioned as the additional medium 
for course delivery. The video and other supplemented tools also enabled the lecturer and students to experience the virtual learning as if they were in the traditional face-to-face classroom.

In addition, the challenges occur during the learning process since the key characteristic of distance learning is the physical separation of lecturer from the students. Technology becomes the medium of academic interaction. The learners and the learning context are the center of learning process (White, 2009). Distance language learning is also considered independent language learning. Independence means that the learners should develop their learning attitudes and strategies in the process of learning the target language. This approach then requires self-reliance and self-initiative (Hurd \& Lewis, 2008). In the real class, lecturer could immediately guide and deeply explain the course materials. The teacher could give support and direct feedback whenever misconception occurred during the learning process. In other words, the real classroom enabled students to share their thought and to discuss the course with their peers compared to asynchronous online learning mode. The interview indicated that the students preferred to learn in traditional face-to-face class since they wanted to have real interaction with lecturers and their friends. They also felt easier to understand the course delivered by lecturer in the real classroom rather than online platforms. In conclusion, the students were highly dependent on lecturer's explanation about the course material and they were less motivated to learn independently and accessed the available writing sources by themselves.

Furthermore, the students had to understand the goal of the course and did greater effort to accomplish it. They had to be more discipline and active than the conventional learning context. Self-autonomy and initiative were highly essential in distance learning and the students should adjust to such learning behaviors. In terms of time management in asynchronous mode of learning, few were lack of self-discipline for they carelessly submitted their tasks any time regardless the given deadline. They seemed not understand that distance learning system was self-centered learning which required students to be more independent in the process of learning. In the first task to write about five sample topic sentences, some of them were lazy to practice writing their original own topic sentences and carelessly cheated from internet.

The next challenge is the skill in operating the platforms. The traditional learning activities in the classroom transform into digital conferences. It is now possible for the learners to design their own learning experiences and strategies (Reinders \& White, 2016). It was undeniable that technology made the learning process simpler than the conventional learning context. In spite of its practical use, the technology evolved and it offered hundreds of new digital platforms which could be used in the learning 
process. The challenge was not only for students but also for the lecturer who needed to continuously upgrade their skill in operating the latest technology.

The Output of Internet-Based Approach in Paragraph Writing Distance Learning The technology of internet can support the learning of basic English skills including writing. ICT fosters students' willingness and interest in the learning process. However, the success of learning does not only depend on the easy access of internet and the ability to operate it but also the students' attitudes and beliefs on the ways they learn the target language (Kenning, 2007). Reinders \& White (2011) further explain that technology certainly enhances students' autonomy in language learning. It offers a lot of opportunities for students to access the authentic materials and to practice their English through cross cultural interaction. Nevertheless, the learning outcome greatly lies on the students' motivation and awareness.

The expected English writing skill in the course of Paragraph-Writing is the ability of students to construct or write a good paragraph in English. Thus, the course materials were designed to meet the goal of the course. In the first task, most students exhibited a good start in writing their own topic sentences. They wrote correct topic sentences which consisted of subject and predicate. Nonetheless, several of their topic sentences were still general or too specific which indicated that they did not pay attention to the instruction and the sample of good topic sentences on the book and audio recording. The lecturer then reviewed their works, re-explained the material, and suggested them to edit them. Below are the examples of students' topic sentences;

Education is the gateway to a better life.

Good health requires a balanced diet, lots of exercise, and a positive attitude.

Many people underestimate the work of housewives.

A good paragraph is a paragraph that has a connection between one sentence and the other.

The most important problem in our city is its poor public transportation system.

In the next task, students showed further progress in writing their supporting sentences and concluding sentence. However, they had not met the standard of good paragraph. They just freely wrote without giving attention to the unity of paragraph. They hence wrote a lot of irrelevant information in each paragraph which did not correlate to each topic sentence. The lecturer then immediately decided to conduct Zoom video conference to deeply explain the subject matter and to give feedback to their task. After joining the live video conference, the students were requested to edit their work and resubmitted them on the Google classroom. The edited works were 
better than previous ones. A few students ultimately understood writing a good paragraph with correct pattern and unity. These are some edited writings of the students.

Digital platform is one media to improve writing skills. First, it can be accessed on any time and place. Second, it provides many features that are easy to use. Third, it provides facilities to share writing among authors. In conclusion, digital platform is the best choice to develop writing ability.

Eating healthy food is important because it helps to maintain a healthy body. There are many high-quality vitamins that can be found in fresh vegetables and organic vegetables. It is good to eat vegetables every day to meet nutritional needs. Shortly, it is better to take care of our health before getting sick by eating nutritious food.

The lecturer only showed two examples of paragraphs which were considered having good structure. Each paragraph was started with topic sentence and was followed by supporting sentences. A student even practiced to use time order signals to organize their sentences and to use conclusion signal to end their paragraph. The other three students did not show significant progress in their works.

Furthermore, the students also exhibited a good writing progress through Steller application. Since they were assigned to share their Ramadan (fasting month for Muslim) experiences every Monday and Thursday. They creatively designed the background of their stories and enjoyed the activities of writing in the application. The lecturer then consistently guided and monitored their stories writing in Steller in order to keep them on the track.

The final writing task published on blogging platforms exhibited on findings represented students' various writing outcome. The first writing seemed enjoy free writing technique and did not use correct grammar and tenses. Besides, there were a lot of unrelated ideas which made the essay lacked of unity and coherence. The second narrative paragraph also tended to apply free writing technique. Even though paragraph used few time orders signals, the writer did not clearly state the topic and concluding sentence. He did not use any signal words to connect his two paragraphs. He also made mistakes on grammar and tenses. Even though there were still grammar mistakes in the third writing, it was quite clear explanation on each step by using sentence connectors. In the fourth writing, the student applied the time order signals yet carelessly made a lot of spelling and grammar mistakes. Both process paragraph did not follow the correct paragraph format and proper punctuation.

The last writing also exhibited dissatisfied result of learning. The student did not indent the first sentence of the paragraph. Meanwhile, the concluding sentence was only the other fact of owl which should support the topic sentence. Besides, the paragraph used improper signal words which 
indicated process. Last, the paragraph did not refer to any type of paragraph having been learned.

To conclude, distance online learning showed dissatisfied output. The students still dealt with the fundamental problems such as grammar, tenses, and vocabularies. However the overall learning process indicated that few students exhibited good progress in terms of exploring and organizing their ideas yet they did not follow the correct paragraph structure and format. Most of them had not clearly stated the topic sentence, supporting sentences, and concluding sentence and their paragraphs still lacked of unity, coherence, and cohesion. The curriculum of distance learning of paragraph writing should be redesigned in order to achieve the satisfied outcome. Primarily, distance learning sytem should be reevaluated in isolated areas with bad internet connection. The lecturer also found synchronous media more effective in distance learning in which students still heavily depended on direct feedback and live communication. Furthermore, the academic stakeholders should reconsider intenet facilities in order to establish fully online distance learning.

\section{CONCLUSION AND SUGGESTION}

The implementation of online distance learning method to Paragraph Writing course was not easy. The lecturer faced difficulty to adjust and to design the course material which fitted online learning platforms. The multisynchronous type of learning was applied in order to obtain the total understanding of the subject matter. Nevertheless, the asynchronous platforms were mostly used regarded the internet connection issue. The challenges were the lack of students' responsibilities and understanding on the concept of self-centered in distance learning. The successful of distance learning also required full support from local government and University board members. They should provide free internet access or other facilities for students living in the isolated area in Barru regency, Indonesia. Besides all the challenges and obstacle faced by all academic members, some students exhibited improved skill of writing English paragraph. Few of them eventually knew to write a good English paragraph. It was undeniable that the learning process was still far from success, and the distance English learning mode should be well prepared to face the future online learning system at STKIP Muhammadiyah Barru, Indonesia.

\section{REFERENCES}

Ahmadi, D. M. R. (2018). The Use of Technology in English Language Learning: A Literature Review. International Journal of Research in English Education. https://doi.org/10.29252/ijree.3.2.115

Alsagoff, L., McKay, S. L., Hu, G., \& Renandya, W. A. (2012). Principles and practices for teaching english as an international language. In Principles 
and Practices for Teaching English as an International Language. https:/ / doi.org/10.4324/9780203819159

Altunay, D. (2019). EFL Students' Views on Distance English Language Learning in a Public University in Turkey. Studies in English Language Teaching. https://doi.org/10.22158/selt.v7n1p121

Cohen, L., Manion, L., \& Morrison, K. (2017). Research Methods in Education. In Research Methods in Education. https://doi.org/10.4324/9781315456539

Demiray, U., \& Sharma, R. C. (2008). Ethical practices and implications in distance learning. In Ethical Practices and Implications in Distance Learning. https://doi.org/10.4018/978-1-59904-867-3

Dudeney, G., \& Hockly, N. (2007). How To Teach English With Technology (J. Harmer (ed.)). Pearson Longman.

Ekmekçi, E. (2015). Distance-education in Foreign Language Teaching: Evaluations from the Perspectives of Freshman Students. Procedia Social and Behavioral Sciences. https:// doi.org/10.1016/j.sbspro.2015.01.487

Holmberg, B., Shelley, M., \& White, C. (2005). Distance Education and Languages Evolution and Change (V. Edwards (ed.)). Multilingual Matters LTD.

Huang, R., Spector, J. M., \& Yang, J. (2019). Educational Technology a Primer for the 21st Century. In Spaces for the Future. https://doi.org/https://doi.org/10.1007/978-981-13-6643-7

Hurd, S., \& Lewis, T. (2008). Language learning strategies in independent settings. In Language Learning Strategies in Independent Settings. https://doi.org/10.21832/9781847690999

Jung, I. (2019). Open and Distance Education Theory Revisited Implications for the Digital Era (I. Jung \& O. Z. Richter (eds.)). Springer Nature Singapore Pte Ltd.

Kenning, M. M. (2007). ICT and language learning: From print to the mobile phone. In ICT and Language Learning: From Print to the Mobile Phone. https://doi.org/10.1057/9780230591325

Lehman, Rosemary M., Conceicao-Runlee, S. (2010). Creating a Sense of Presence in Online Teaching. In Creating a Sense of Presence in Online Teaching: How to "be There" for Distance Learners.

Merriam, S. B. (2009). Qualitative research: A guide to design and implementation. In The JosseyBass higher and adult education series. https:/ / doi.org/10.1097/NCI.0b013e3181edd9b1

Moore, M. G., \& Anderson, W. G. (2003). Handbook of Distance Education. Lawrence Erlbaum Associates.

Negash, S., Whitman, M. E., Woszczynski, A. B., Hoganson, K., \& Mattord, H. (2008). Handbook of distance learning for real-time and 
asynchronous information technology education. In Handbook of Distance Learning for Real-Time and Asynchronous Information Technology Education. https://doi.org/10.4018/978-1-59904-964-9

Nguyen, T. T. L. (2019). Using ICT to foster collaborative writing for EFL university students in Vietnam. Edith Cowan University.

Reinders, H., \& White, C. (2011). Learner autonomy and new learning environments. Language, Learning and Technology.

Reinders, H., \& White, C. (2016). 20 years of autonomy and technology: How far have we come and where to next? In Language Learning and Technology.

Rogers, P., Berg, G., Boettcher, J., Howard, C., Justice, L., \& Schenk, K. (2009). Encyclopedia of Distance Learning. Information Science Reference.

Rosenthal, J. W. (2013). Handbook of undergraduate second language education. In Handbook of Undergraduate Second Language Education. https://doi.org/10.4324/9781410605016

Sritulanon, A., Chaturongakul, P., \& hammetar, T. T. (2018). English Speaking Teaching Model in Distance Education. Arab World English Journal. https://doi.org/10.24093/awej/vol9no3.28

Stake, R. E. (2010). Qualitative Research: Studying How Things Work, The Guilford,. In (2010). Qualitative research: Studying how things work. ix, 244 pp. New York, NY, US: Guilford Press; US.

Warschauer, M., \& Kern, R. (2000). Network Based Language Teaching: Concepts and Practice. Cambridge University Press.

White, C. (2003). Language Learning in Distance Education. In Language Learning in Distance Education. https://doi.org/10.1017/cbo9780511667312

White, C. (2006). Distance learning of foreign languages. Language Teaching. https://doi.org/10.1017/S0261444806003727

White, C. (2007). Innovation and Identity in Distance Language Learning and Teaching. Innovation in Language Learning and Teaching. https://doi.org/10.2167/illt45.0

White, C. (2009). Towards a Learner-Based Theory of Distance Language Learning: The Concept of The Learner-Context Interface. In P. Hubbard (Ed.), Computer Assisted Language Learning: Critical Concepts in Linguistics (pp. 97-111). Routledge.

White, C., \& Reinders, H. (2010). The theory and practice of technology in materials development and task design. In N. Harwood (Ed.), English Language Teaching Materials:Theory and Practice (pp. 58-80). Cambridge University Press.

Zhong, Y. (2008). A Study of Autonomy English Learning on the Internet. English Language Teaching. https://doi.org/10.5539/elt.v1n2p147 